Article

\title{
Local Selling Decisions and the Technical Efficiency of Organic Farms
}

\section{Luanne Lohr ${ }^{1}$ and Timothy Park ${ }^{2}$ *}

1 Food and Specialty Crops, Economic Research Service, USDA, 1800 M. St. NW, Washington, DC 20036-5831, USA; E-Mail: 1lohr@ers.usda.gov

2 Food Marketing Branch, Economic Research Service, USDA, 1800 M. St. NW, Washington, DC 20036-5831, USA

* Author to whom correspondence should be addressed; E-Mail: tapark@ers.usda.gov; Tel.: +1-202-694-5446; Fax: +1-202-694-5662.

Received: 16 November 2009 / Accepted: 5 January 2010 / Published: 11 January 2010

\begin{abstract}
The primary purpose of this paper is to examine the factors that influence earned income of organic farmers explicitly incorporating farmer decisions to engage in local selling. The stochastic frontier model identifies role model producers who are the most technically efficient in achieving the maximum output that is feasible with a given set of inputs along with farm and demographic factors that enhance efficiency. Organic earnings equations that control for producer and farm characteristics reveal that organic farmers who are involved in local sales achieve lower earnings. Producer involvement in local sales has little impact on observed technical efficiency on organic farms.
\end{abstract}

Keywords: local foods; technical efficiency; stochastic frontier; Organic Farming Research Foundation

\section{Introduction}

An emerging agricultural marketing issue is the increased emphasis on the promotion of local food systems that reduce "food miles" and transportation costs while offering consumers the benefits of locally grown food. The American Farmland Trust [1] developed a program for the city of San Francisco to support growing, processing, and consumption of local food (food grown 
within 100 miles of the Golden Gate Bridge) and claimed that "closing the gap between local production and local consumption of food can increase profitability for producers." Agricultural policy makers have suggested that switching to local distribution channels such as farmers' markets or direct sales may allow producers to achieve higher margins and increase their incomes [2].

Darby et al. [3] suggested that marketing foods as "locally grown" is an opportunity for farmers to expand their share of consumers' food budgets and their empirical work demonstrates how consumers value locally grown products. Most of this research focuses on the consumer benefits of locally grown food products. Positive impacts of local sales for producer's are mentioned but are not linked to the sustainability of the farm operation or quantified to any degree. Born and Purcell [4] are a prominent exception in warning local planners and economic development specialists to avoid the "local food trap" that assumes local foods inherently offer desirable qualities such as ecological sustainability, better nutrition, food security, freshness and quality.

The "Know Your Farmer, Know Your Food" initiative builds on the 2008 Farm Bill to strengthen USDA programs promoting local foods and includes plans to enhance direct marketing and farmers' promotion programs, to support local farmers and community food groups, to strengthen rural communities and to promote local eating. The "Know Your Farmer, Know Your Food" website (http://www.usda.gov/knowyourfarmer) lists opportunities for farm loan programs such as direct and guaranteed ownership loans for beginning farmers and socially disadvantaged groups, farm storage facility loans, value-added producer grants, beginning farmer and rancher development programs, and technical assistance and marketing services for farmers engaged in local selling.

The primary purpose of this paper is to examine the factors that influence earned income of organic farmers explicitly incorporating the farmer's decision to engage in local selling. Survey data on the volume of organic products delivered by the organic farmers to product buyers within 100 miles of the farm is used to define local sales. The econometric model is based on a stochastic frontier approach that recognizes that farmers may not be able to achieve maximum output that is feasible with a given set of inputs. The approach identifies the role model producers who are the most technically efficient along with farm and demographic factors that enhance efficiency. A primary innovation of the research is the inclusion of the local marketing option in the stochastic frontier model.

The empirical work recognizes that organic farmers traditionally have utilized a variety of marketing channels to ensure the sustainability of their operations including direct to consumer sales, direct marketing to grocery retailers and restaurants, and sales through packers, brokers and food processors. They have participated in the rejuvenation of farmers markets and innovations such as community supported agricultural (CSA) operations. Extension experts such as Stephenson and Lev [5] have noted the wide variety of direct marketing outlets and the new outlets that have developed to promote local selling initiatives.

The evidence suggests that organic farmers are flexible in adapting their marketing patterns to enhance the profitability of their farms and are willing to develop the capacity and technical skills to sell their commodities in local markets. The $4^{\text {th }}$ Organic Farming Research Foundation (OFRF) survey showed that the share of organic products marketed directly to consumers reached almost 50 percent in 2001 [6]. An analysis of the factors that influence the decision to sell locally could assist organic farmers in formulating better selling strategies. 
The article is organized as follows. The foundations of the stochastic frontier approach are outlined and the information obtained from the model is presented. The survey and data used to estimate the model along with empirical results are then discussed. Offermann and Nieburg's [7] analysis of organic farms in Europe stressed that economic performance, defined as monetary returns to all farm activities related to organic farming, is an appropriate measure to assess the sustainability and efficiency of organic operations. The paper concludes with a discussion of the implications for producers, marketing specialists, and extension experts when guiding organic producers who are considering decisions to engage or expand their efforts in local selling.

\section{Modeling Efficiency in Organic Production}

Stochastic production frontier models, summarized in comprehensive detail in Kumbhakar and Lovell [8], allow for both technical inefficiency and random shocks that are uncontrolled by producers. Stochastic frontier analysis assumes a composite error term consisting of two random variables. The first element in the composite error, $v_{i}$, is a symmetric noise term reflecting random noise which influences farmer decisions and can take on both positive and negative values. The asymmetric inefficiency error term, $\mathrm{u}_{\mathrm{i}}$, accounts for technical and managerial constraints and assumes only nonnegative values. A typical specification for a stochastic frontier model is:

$$
\ln y=\ln f\left(x_{i}, r_{i}\right)+v_{i}-u_{i}
$$

where $y_{i}$ represents the observed output (here, earnings from organic production) measure for the $i^{\text {th }}$ farm, $\mathrm{f}\left(\mathrm{x}_{\mathrm{i}}, \mathrm{r}_{\mathrm{i}}\right)$ is the deterministic frontier with inputs $\mathrm{x}$ with farm, demographic, and regional effects denoted by $r_{i}$. The $v_{i}$ are mean zero i.i.d. random variables with a variance of $\Phi_{v}^{2}$ and are assumed to be independent of $\mathrm{u}_{\mathrm{i}}$ and the explanatory variables. Technical inefficiency is represented by the one-sided error term, $\mathrm{u}_{\mathrm{i}}$, following a half-normal distribution with a variance $\Phi_{\mathrm{u}}^{2}$. Techniques for estimating the stochastic frontier by maximum likelihood are presented in Kumbhakar and Lovell [8].

The one-sided error term $u_{i}$ is interpreted as the distance to the best-practice stochastic frontier represented by $\ln y_{i}=\ln f\left(x_{i}, r_{i}\right)+v_{i}$. The best practice corresponds to the maximum output the organic farmer is expected to produce given inputs that are applied and characteristics of the farm operation and producer that are included as explanatory variables.

The frontier production function for the $\mathrm{i}^{\text {th }}$ producer is specified using a translog functional form for inputs along with measures of the marketing and environmental constraints facing organic producers. The input variables in the model include full-time labor inputs (FLABR), part-time labor (PLABR), and organic acreage (ACRE). Farm level organizational and environmental factors $\left(r_{\mathrm{ji}}\right)$ that directly influence production are incorporated into the model. The second-order terms in the translog production frontier in Equation 1 are represented by k(FLABR, PLABR, ACRE) with estimated coefficients of $\alpha_{\mathrm{ij}}$. The logarithm of total value of organic production (PRODVAL) is the dependent variable in the production frontier. The stochastic frontier model is: 


$$
\begin{gathered}
\ln \text { PRODVAL }=\alpha_{0}+\alpha_{1} \ln \left(\text { FLABR }_{i}\right)+\alpha_{2} \ln \left(\text { PLABR }_{i}\right)+\alpha_{3} \ln \left(\text { ACRE }_{i}\right)+ \\
\alpha_{i j} k_{\left(\text {FLABR }_{i}, \text { PLABR }_{i}, \text { ACRE }_{i}\right)+\sum_{j} \gamma_{j} r_{i j}+v_{i}+u_{i}}
\end{gathered}
$$

Technical efficiency is estimated as $\mathrm{TE}_{\mathrm{i}}=\exp \left(-\hat{\mathrm{u}}_{\mathrm{i}}\right)$, which has a value between 0 and 1 , with 1 indicating an efficient organic farm and that the producer is located on the frontier. Only the difference between the random error terms $\varepsilon i=v i-u i$ can be observed, requiring a derivation to extract technical efficiency ui from ei. Kumbhakar and Lovell [8] summarize methods to obtain estimates of technical efficiency for each producer by deriving $a \mathrm{i}$ from the conditional distribution $\mathrm{E}(\mathrm{ui} \mid \varepsilon \mathrm{i})$ which are implemented in LIMDEP ([9]).

The analysis focuses on the impact of short-run adjustments in variable inputs such as the labor inputs and certified acreage on the value of organic production, a model specification which is consistent with the stochastic frontier model in Kurkalova and Carriquiry [10]. A more extensive model could incorporate data on farming and management practices for controlling crop diseases and nematodes, insect pest techniques, and weed control methods. Information on these variables was considered for inclusion as quasi-fixed inputs that proxy for capital and equipment used in the organic operation. The OFRF survey elicited information on adopted practices, derived from responses to three separate questions related to crop disease and nematode management, insect pest controls, and weed controls. In previous modeling efforts, these variables had no statistically significant impacts on the value of production of the organic farmers and are omitted from the analysis. Information on capital used directly in the organic farming operation was not available in the OFRF survey.

\section{Modeling Efficiency in Organic Production}

Analysis on a scale broad enough to accurately reflect the production conditions must be drawn from a national survey that is representative of all organic farmers. Since 1993, the private not-for-profit OFRF has conducted biennial surveys of organic farmers in the U.S. The OFRF queried the entire U.S. certified organic farm population, as identified by organic certifiers in 1997. Lohr and Park [11] have established the representativeness of the data by comparing survey response records with production statistics collected by the U.S. Department of Agriculture. The information on the types of sales outlets used by the farmer is only available from the OFRF survey.

The data combine information on all crops grown organically and all regions in which organic crops are produced in the U.S. Table 1 details the descriptions and summary statistics for variables in the model estimated following Equation 1. Natural $\log s$ of the variables reported in Table 1 were used in estimation where appropriate. The logarithm of total organic farming gross income (PRODVAL) is the dependent variable, consistent with the specification in Fraser and Horrace [12] and Mathijs and Swinnen [13] and many others. Mean gross organic income for the farmers was $\$ 146,048$. 
Table 1. Variable descriptions and summary statistics ( $\mathrm{N}=787$ farms).

\begin{tabular}{llrc}
\hline Variable & Description & Mean & $\begin{array}{r}\text { Standard } \\
\text { Deviation }\end{array}$ \\
\hline PRODVAL & Total value of organic production, U.S. dollars (US\$) & 146,048 & 607,488 \\
FLABR & Managers and full-time employees & 2.6 & 4.5 \\
PLABR & Part-time employees & 5.1 & 23.6 \\
ACRE & Acreage farmed organically, 1 to 6,000 acres & 193.4 & 680.4 \\
LOCPCT & Organic production sold within 100 miles of the farm & 57.1 & 46.3 \\
& operation, percent & & \\
TRANMIXD & Producer transitioned to organic farming and farms & 15.8 & 36.5 \\
& both organic and conventional acreage, 1 if yes & & \\
FULLPART & Part-time organic farmer, 1 if yes & 31.4 & 46.4 \\
MALE & Producer is male, 1 if yes & 79.1 & 40.6 \\
SOLEFAML & Farm is a sole proprietorship or family-owned, percent & 92.6 & 26.1 \\
& of total & & \\
COOPCRPR & Farm operation is organized as a non-family, & 5.0 & 21.7 \\
& partnership, corporation, or cooperative, percent & & \\
WEST & of total & & \\
SOUTH & Farm is in SARE Region 1, percent of sample & 28.6 & 45.2 \\
NOREAST & Farm is in SARE Region 3, percent of sample & 5.7 & 23.2 \\
NORCENT & Farm is in SARE Region 4, percent of sample & 25.4 & 49.1 \\
\hline & Farm is in SARE Region 2, percent of sample & 25.4 & 43.6 \\
\hline
\end{tabular}

\subsection{Production Inputs}

The variable production inputs given in Equation 1 are two labor measures and organic acreage, assumed to be entirely under the control of the producer, and both subject to change annually depending on the planned output for that season. The labor input is represented by year-round workers and seasonal farm employees. The majority of organic farm operations (52 percent) relied on both year-round and seasonal workers with 34 percent of farms hiring only seasonal workers and 14 percent using only year-round workers. Employment of both year-round and seasonal farm workers is more closely correlated with farm income than is farm size and the relationship is even stronger for organic farms with higher incomes (over \$99,000). Farmers focusing on local sales employ the fewest number of both year-round and seasonal workers.

The mean farm size in the sample was 193 acres, with the largest farm in the sample operating at 13,000 acres. Organic farm size is most strongly related to production of field crops with a correlation coefficient of 0.73 , followed by vegetable production at 0.21 , and fruit, nut and tree crop production at 0.01 . Larger farms tend to include field crop and vegetable production.

\subsection{Farm, Demographic, and Regional Variables}

Additional explanatory variables in the specification, constituting $\mathbf{r}_{\mathbf{j i}}$ in the stochastic frontier, are the farm, demographic, and regional factors that influence the production frontier. These are not 
production inputs, but may alter the inclination and ability of the farmer to respond optimally to production constraints.

The producers indicated the volume of organic products delivered to product buyers within 100 miles of the farm and this information is used to define the producer's use of local sales outlets (LOCPCT). Three main commodity categories were identified based on the production data gathered in the OFRF survey: (1) vegetable, herb, and floriculture products, (2) fruit, nut, and tree products, and (3) grain and field crops. There is no formal definition of local sales but the 100 mile limit is fully consistent with working definitions that are used by the food industry. Whole Foods, the world's largest natural foods retailer, features its Locally Grown promise with a commitment to buying from local producers, particularly those who farm organically and are dedicated to environmentally sustainable agriculture [14]. Produce that has traveled seven or fewer hours by car or truck from the farm to the retail outlet can be labeled "locally grown".

For organic farms engaging in local selling the correlation between organic farm earnings and the hiring of seasonal workers is strongly positive (at 0.82 ), rising 40 percent relative to the correlation across all organic farms. The positive correlation of earnings with year-round workers is stable and about the same as for all organic farms (0.34). The pattern is in sharp contrast to that observed for farms that do not sell any products in local markets. For these producers earnings are more strongly correlated with year-round workers (0.43) and the relationship between earnings and seasonal workers is quite small (0.16). Organic farms with a local sales emphasis typically employ fewer total workers and hiring rates of both year round and seasonal workers for the local sales farms are smaller compared with other organic producers.

Under the U.S. regulations, farmers may certify as organic less acreage than they farm, leading to parallel organic and conventional systems being managed by the same operator. Only 18 percent of the OFRF respondents reported conducting this type of mixed farming. Farmers who were originally conventional producers but transitioned to organic production accounted for 52 percent of the OFRF respondents, compared with 48 percent who began farming as organic producers. The subset of farmers who transitioned to organic farming but maintained mixed farming operations was about 16 percent of operations. These producers were expected to have more familiarity with extension advisors to locate markets and deal with marketing problems along with an enhanced capability to maintain income levels as they continue to use conventional production techniques.

Farm structure variables for family operated farms (sole proprietorship or family corporations) and corporate organizations reflect the potential flexibility accorded the farmer in making management decisions. Family operated farms offer the greatest management flexibility to the farmer because they involve the least number of other decision makers. Corporations offer the least flexibility and have relatively more demanding financial and reporting requirements. The family farm category accounts for about 92 percent of the organic farms with corporations accounting for the second largest share at 4 percent. Alternative farm structures representing a third, intermediate level of flexibility, including partnerships and property management firms, were grouped in the omitted category. Overall about 32 percent of the organic producers were engaged in farming on a part-time basis.

The USDA has placed increasing emphasis on research, technical and marketing assistance focusing on the management concerns of female farmers. Female farmers comprise 21 percent of U.S. organic farms. Recognizing that more women are choosing to manage their own farms, the 
Cooperative State Research, Education and Extension Service (CSREES) has stated that a primary policy goal is to provide women farmers with the tools they need to succeed. Female producers tend to sell greater shares of their output in local markets with 67 percent selling to outlets within 100 miles of the farm while 49 percent of males show this level of commitment to local sales.

To assess institutional support and information availability for organic production and marketing systems, we used the four USDA Sustainable Agriculture Research and Education (SARE) regions (see http://www.sare.org/htdocs/sare/about.html for a listing of states in each region). These regions reflect the U.S. government's demarcation for sustainable agriculture extension-research support. A dichotomous variable was created for each region, equal to one if the respondent's farm was in that region, and zero otherwise. In the sample, 29 percent of farmers were in the SARE 1 region (WEST), 40 percent in the SARE 2 region (NORCENT), 6 percent in the SARE 3 region (SOUTH), and 25 percent in the SARE 4 region (NOREAST).

The West region has historically received the strongest institutional support for organic agriculture, being home to two of the nation's oldest organic farm and certifying organizations, California Certified Organic Farmers, and Oregon Tilth. California enacted the first state law to define organic foods in 1982. California and Washington were among the first extension services to conduct outreach and applied research on organic agricultural systems using teams of extension professionals rather than individuals. Thus, the locality-specific research needed for successful organic farming emerged sooner in the West than in the other regions. Estimation results are expected to show higher efficiency in the West region.

\section{Estimation Results}

Coefficient estimates and asymptotic t-ratios for the stochastic frontier shown in Equations 1 and 2 are presented in Table 2. Random shocks that influence the earnings of organic farmers are assumed to be related to acts of nature such as weather, pest and weed infestations, and yield variability that are endemic to organic production. Zellner, Kmenta, and Dreze [15] noted that when producers maximize expected profit rather than ex post profit, the error terms for inputs can be assumed to be driven by human error and managerial misjudgments which should be unrelated to the error term in the stochastic production function. The restrictions consistent with a Cobb-Douglas functional form which would omit the quadratic and interaction terms for the land and labor inputs were rejected. The calculated $\chi^{2}$ value of 40.11 exceeds that critical value of $\chi_{6}^{2}$ of 12.59 at any reasonable confidence level.

We conducted a Hausman exogeneity test of the LOCSELL measure. Intuitively the random shocks to organic earnings for a farmer would not show a high degree of correlation with the local selling measure. The decision to sell $100 \%$ of a commodity through local markets represents a long-term plan of the producer and can be considered as predetermined in the econometric model. The farmer must exhibit knowledge of the local market, develop a business plan, and develop appropriate marketing aids. These decisions require extensive planning and should not be highly influenced by short-term production shocks. Instruments included the marketing aids used by the producer in selling through local outlets (such as farm events and demonstrations, local promotional efforts, featured product samples, and in-store demonstrations), the development, promotion, and sales of value added products 
on the farm, the age of the producer, and the farmer's experience in growing and marketing organic crops (in years). These measures should be correlated with success in stimulating local sales but are determined prior to the short-term random shocks that influence output and earnings at the farm level. The exogeneity hypothesis for the local selling measure was not rejected. The test statistic confirms that endogeneity is not a significant factor in the specification of the production function as the calculated $\chi^{2}$ value of 2.28 was below the critical value $\chi_{1}^{2}$ at any conventional significance level.

Table 2. Stochastic Frontier Parameter Estimates for Organic Producers ( $\mathrm{N}=787$ farms).

\begin{tabular}{|c|c|c|c|}
\hline Parameter & Variable & Estimate & T-ratio ${ }^{a}$ \\
\hline \multicolumn{4}{|c|}{ Vector $\alpha_{i}$-Inputs } \\
\hline$\alpha_{0}$ & Constant & $10.054 *$ & 32.872 \\
\hline$\alpha_{1}$ & $\ln ($ FLABR $)$ & $0.248 *$ & 1.840 \\
\hline$\alpha_{2}$ & $\ln (\mathrm{PLABR})$ & $0.223 *$ & 2.313 \\
\hline$\alpha_{3}$ & $\ln (\mathrm{ACRE})$ & -0.041 & -0.581 \\
\hline \multicolumn{4}{|c|}{ Vector $\alpha_{\mathrm{ij}}$-Interactions } \\
\hline$\alpha_{11}$ & $\ln ($ FLABRSQ) & $0.311 *$ & 3.963 \\
\hline$\alpha_{22}$ & $\ln ($ PLABRSQ) & 0.055 & 0.939 \\
\hline$\alpha_{33}$ & $\ln (\mathrm{ACRESQ})$ & $0.073 *$ & 3.720 \\
\hline$\alpha_{12}$ & $\ln ($ FLABR $) \times \ln ($ PLABR $)$ & $-0.125^{*}$ & -2.722 \\
\hline$\alpha_{13}$ & $\ln (\mathrm{FLABR}) \mathbf{x} \ln (\mathrm{ACRE})$ & -0.005 & -0.162 \\
\hline$\alpha_{23}$ & $\ln (\mathrm{PLABR}) \mathbf{x} \ln (\mathrm{ACRE})$ & 0.036 & 1.607 \\
\hline \multicolumn{4}{|c|}{ Vector $\gamma_{j}$-Farm, Demographic, and Regional Variables } \\
\hline$\gamma_{1}$ & LOCPCT & $-0.214^{*}$ & -2.470 \\
\hline$\gamma_{2}$ & TRANMIXD & $-0.199 *$ & -1.892 \\
\hline$\gamma_{3}$ & FULLPART & $-0.836^{*}$ & -9.402 \\
\hline$\gamma_{4}$ & MALE & $0.174 *$ & 1.888 \\
\hline$\gamma_{5}$ & SOLEFAML & 0.119 & 0.498 \\
\hline$\gamma_{6}$ & COOPCRPR & $0.628^{*}$ & 2.193 \\
\hline$\gamma_{7}$ & WEST & $0.170 *$ & 3.050 \\
\hline$\gamma_{8}$ & SOUTH & $-0.271^{*}$ & -1.770 \\
\hline$\gamma_{9}$ & NOREAST & 0.026 & 0.351 \\
\hline$\gamma_{10}$ & NORCENT & $-0.115^{*}$ & -2.621 \\
\hline$\lambda$ & LAMBDA & $0.744^{*}$ & 7.798 \\
\hline$\sigma$ & SIGMA & $1.148^{*}$ & 961.506 \\
\hline
\end{tabular}

\footnotetext{
${ }^{\mathrm{a}}$ Asterisk indicates asymptotic t-values with significance at $\alpha=0.10$ level;

${ }^{\mathrm{b}}$ The definition of $\lambda=\sigma_{\mathrm{u}} / \sigma_{\mathrm{v}}$ and $\sigma=\left(\sigma_{u}^{2}+\sigma_{v}^{2}\right)^{1 / 2}$.
}

\subsection{Output Elasticities and Scale Measures}

Using the estimated model, the coefficient estimates for the natural logs of the inputs are converted to output elasticities. The elasticities are calculated by taking the derivatives of the estimated coefficients with respect to the logarithms of each input measure. The output elasticities measure the change in the value of organic farm production in response to a specified change in the use of an input. 
The resulting output elasticities indicate that a one percent increase in full-time labor used increases the value of organic production by 0.47 percent, with a smaller impact of 0.26 percent for more part-time labor. The estimated elasticity for full-time labor is statistically higher than the elasticity for part-time labor.

An expansion of the acreage farmed by one percent increases the value of organic production by 0.22 percent. Higher input levels lead to increased organic production value ensuring that the monotonocity condition for the production function is met for each input (full-time and part-time labor and organic acreage). Concavity of the production function is satisfied if the Hessian matrix based on the parameter estimates is negative semidefinite and this condition is satisfied for the model.

Incorporating the interaction terms permits consideration of an overall scale effect on production. The output elasticities for labor and acreage were each evaluated for farms in four acreage size percentiles (0-25th percentile, 26-50th percentile, 51st-5th percentile, and 75th-100th). The sum of the output elasticities is the scale elasticity, which measures how output changes when the producer increases the use of both inputs. The estimated scale elasticity increases with the size of the farm, moving from decreasing returns to scale for smaller farms to increasing returns to scale for the farms with the most organic acreage. Producers with farms exceeding 120 acres show slightly increasing returns to scale. Serra and Goodwin [16] also report increasing returns for organic farmers and are consistent with results from an earlier OFRF survey reported by Lohr and Park [17].

The finding from Table 2 show that after controlling for producer and farm characteristics, organic farmers who are involved in local sales achieve lower earnings, an effect which is statistically significant. The significant negative coefficient on the measure of the producer's involvement in local selling indicates that a 1 percent increase in the volume of output sold in local markets is associated with a decline in gross income from organic production of about 21 percent on average. This implies a decrease in organic earnings of about $\$ 31,194$ dollars for the average organic farm. Our findings identify a negative relationship between an increased emphasis on local sales and earnings by organic farmers. The impact of local sales on net earnings or profitability is not directly measured.

A set of the explanatory variables (TRANMIXD, FULLPART, MALE, and COOPCPR) all generated significant coefficient estimates. The variables that are dichotomous indicators cannot be differentiated to evaluate marginal effects so we use Kennedy's [18] procedure to measure their impacts on the value of organic farm production. Farmers who transitioned to organic farming and maintain mixed farming operations have earned income that is about 18 percent lower than other types of producers, $\exp (-0.199)-1=-0.18$. Producers engaged in part-time farming accrue earnings that are about 57 percent lower than full-time organic farmers. This decline is exacerbated when the part-timers decide to engage in local sales as the combined effects of the two variables results in an income decline of about 78 percent.

The model shows that male farmers achieve earnings that are about 19 percent higher than female operators even after controlling for key farm, demographic and regional effects. As they intensify their marketing efforts in local sales outlets, male farmers experience only a slight earnings decline of about 2.3 percent. The earnings decline associated with involvement in local sales is much higher for female farmers compared to males. Experience with organic farming does not appear to be a factor driving the larger earnings decline for female farmers. Using data from the OFRF survey the number 
of years involved in organic farming is virtually the same (about 12 years) for both the female and male farmers.

The geographic variable estimates compare regional organic production value with the average for all U.S. organic farms. The null hypothesis that the regional effects are jointly equal to zero is rejected at $\alpha=0.05$ while the positive coefficient for the West region and the negative coefficient for the North Central region are statistically significant. Estimated regional indicator coefficients presented on Table 2 were normalized as deviations from the acreage-weighted mean farm coefficient. We use a technique from Krueger and Summers [19] that is implemented to assess the impact of each regional indicator variable directly while avoiding the dummy variable trap. These measures are independent of any arbitrarily chosen base region and provide a clearer interpretation of how the complete set of regional effects influences organic production values.

Farms located in the West region have gross organic production values 17 percent higher than the average U.S. organic farm, consistent with the early and continuing institutional support for organic agriculture in this region. Those farms in the North Central region have gross organic production values about 12 percent below the average U.S. organic farm. This may be due to emphasis on field crop production in the region, which tends to return lower gross income per acre than vegetable and fruit crops.

\subsection{Technical Efficiency Associated with Participation in Local Sales}

A test of the importance of technical inefficiency in the model is confirmed by the statistical significance of the estimated 8 of 0.744 . The ratio of the standard deviation of the producer-specific technical efficiency to the overall standard deviation of the producers' income is 0.356 . The interpretation is 35.6 percent of the variation in earnings from organic production across farms is due to technical efficiency.

Table 3 summarizes the overall technical efficiency for the stochastic frontier model and an efficiency decomposition using information on participation in local sales. The estimated mean technical efficiency score is $\mathbf{5 8 . 7}$ percent for the entire sample, indicating that the organic farmers are not implementing best-practice production methods to achieve the maximum output levels given the inputs used. The mean output-oriented measure of technical efficiency shows that output could feasibly be increased by 41.3 percent with current input use under current production technology. Using data from the Third Biennial National Organic Farmers' Survey, Lohr and Park [17] estimate a mean technical efficiency score of 78.8 percent. There is some tentative evidence of a decline in technical efficiency of organic producers. The estimates are not directly comparable since the additional information on marketing outlets is only available in the most recent survey conducted by the OFRF and the surveys do not represent panel data with the same set of producers. 
Table 3. Efficiency Decomposition for Local Sales Participation $(\mathrm{N}=787)$.

\begin{tabular}{|c|c|c|c|c|c|}
\hline & Observations & Mean & $\begin{array}{l}\text { Standard } \\
\text { Deviation }\end{array}$ & Minimum & Maximum \\
\hline Overall Efficiency & 787 & 58.7 & 9.4 & 22.1 & 83.5 \\
\hline \multicolumn{6}{|c|}{ By Percent of Production Sold in Local Markets } \\
\hline 100 percent & 361 & 58.4 & 8.9 & 27.2 & 79.2 \\
\hline Some involvement & 157 & 60.1 & 8.7 & 29.1 & 78.3 \\
\hline 0 percent of production & 269 & 58.3 & 10.1 & 22.1 & 83.4 \\
\hline \multicolumn{6}{|c|}{ By Percent of Production Sold in Local Markets } \\
\hline \multicolumn{6}{|c|}{ Males } \\
\hline 100 percent & 269 & 58.1 & 8.8 & 27.2 & 79.2 \\
\hline 0 percent of production & 219 & 58.8 & 9.8 & 24.1 & 83.5 \\
\hline \multicolumn{6}{|l|}{ Females } \\
\hline 100 percent & 92 & 59.2 & 9.3 & 33.7 & 74.9 \\
\hline 0 percent of production & 41 & 56.0 & 11.7 & 22.1 & 74.5 \\
\hline
\end{tabular}

Reinhard, Lovell, and Thijssen [20] regarded their calculated mean technical efficiency of 89 percent for Dutch dairy farms as "impressively high." Serra and Goodwin [16] reported a mean efficiency of 94.0 percent for organic crop farms in the Spanish region of Andalucia. Even at this very high level, the efficiency of the organic farms is below that of the conventional farms in the sample with estimated scores of 97.0 percent. Estimates of technical efficiency for Finish dairy farms from Kumbhakar, Tsionas and Sipiläinen [21] are approximately 79.6 percent and the organic farms are about 5 percent less efficient than the conventional dairy farms. Organic farming subsidies are prominent in these countries and these payments may induce entry by inefficient farmers.

The technical efficiency estimates suggest that producer involvement in local sales has little impact on observed efficiency on organic farms. Farmers who sell all of their output in local markets have a mean efficiency score of 58.7 percent. This performance is only marginally lower than the score of 60.1 percent attained by organic farmers who sell some but not all of their output in local outlets. This important result suggests that the decision to sell in local markets does not induce distortions in the technical efficiency of organic farmers. The decision to sell in local markets is not a critical factor distorting the performance of organic farmers.

The stochastic frontier model is also useful in providing a clearer view of how gender influences the performance of organic farmers. We examined the technical efficiency of organic farmers who commit to selling all their output in local markets. Table 3 shows that the technical efficiency of female farmers is slightly higher than male farmers for this set of producers. Kotcon and Thilmany [22] commented that "...extension programs must be tailored to the unique needs and learning styles of the organic community within appropriate venues to successfully reach growers." The stochastic frontier model shows extension agents and agricultural marketing consultants that female farmers have achieved a level of technical efficiency that matches males but may need additional information and training directed to marketing of organic products. 


\section{Conclusions}

The concept of locally grown food is gaining increasing prominence as a marketing and sales strategy for small farmers and organic producers. Wal-Mart offers local food vendors marketing assistance to supply its flagship stores and Sam's Clubs and presents training sessions to teach prospective suppliers how to win favor with Wal-Mart purchasers. Coley et al. [23] mentioned a diverse set of criteria that can be used to evaluate the impact of local purchasing decisions including implications for biodiversity and landscape, local employment, and fair trade. We focus on a factor that has been neglected in current discussions on local sales by examining how earnings are influenced by marketing strategy, specifically the decision to sell in local markets.

The results provide information for organic farmers to assess how the sustainability of their farm operations is influenced by involvement in local sales. A similar point is made by Gilg and Battershill [24] who emphasized that the sustainability of farm systems can be enhanced by evaluating the economic effects associated with specific marketing practices. Earnings equations that control for producer and farm characteristics reveal that organic farmers who are involved in local sales achieve lower gross farm earnings.

A second key finding is the increasing returns to scale in organic farming based on translog function for full-time labor, part-time labor, and organic acreage. This result might be troubling to family farm proponents. One of the most divisive issues in organic agriculture today is the small vs. large argument, in which it is claimed that increasing farm sizes are hastening the industrialization of the organic sector and undermining the philosophical tenets that distinguish organic from conventional agriculture. The results presented here suggest that economic gains will be realized as farm size increases, creating pressure on organic farmers to expand operations. Protecting the small organic farmer is likely to become a policy issue in the near future.

Overall technical efficiency estimates confirm that organic farmers are not implementing best-practice production methods to achieve the maximum output levels given the inputs used. A useful finding is that producer involvement in local sales has little impact on observed efficiency on organic farms. The decision to sell in local markets is not a critical factor distorting the performance of organic farmers.

Our approach treats all organic producers with a single production function and the specification could serve as a useful starting point for considering more detailed subgroups of producers and specific combinations of marketing outlets. Identifying the most efficient producers and observing and testing their methods are the first steps in developing the information needed to assist less successful farmers. To the extent it is possible to transfer this knowledge and implement new technologies the productivity of the entire organic farm sector can be improved.

The stochastic frontier model is useful in identifying the best performers conditional on a marketing strategy, providing role models who can disseminate successful methods to other producers. Identifying the most efficient producers and observing and adapting their methods are the first steps in developing the information needed to assist new farmers and less successful current farmers. To the extent it is possible to transfer this knowledge and implement new marketing techniques, the productivity of the entire organic production sector can be improved. 
The current format of the OFRF survey distinguishes between family and non-family labor but does not indicate how labor is allocated to specific tasks on the operation. Information on labor allocated to tasks such as production, planting and harvesting could be differentiated from work requirements related to post harvesting, processing and marketing tasks in future OFRF surveys.

Additional research is warranted to identify the channel management techniques used by organic producers to maximize returns from local sales efforts. Organic farmers involved in local sales are faced with an array of contracting arrangements and pricing strategies, such as spot markets, short-term forward contracts, or long-term forward pricing. Local marketing channels may feature a variety of pricing strategies, packaging, or service provision requirements. These elements should be investigated to assist organic farmers in maximizing returns when considering local sales initiatives.

In future work the long-term effects of the local sales commitment along with the technical expertise and marketing experience of the organic farmer can be incorporated directly as factors influencing the technical efficiency of the production system through the error term in the stochastic frontier. Key explanatory variables such as local sales involvement, education, and organic farming experience can appear as explanatory variables influencing the technical inefficiency component of the one-sided error term. This is consistent with the approach used by Morrison-Paul, Johnston, and Frengley [25] examining the impact of measures that influence both the technological structure of production and technical efficiency at the farm level.

More advanced models based on the marketing literature could be formulated to understand how farmers develop marketing and sales strategies and allocate their sales across local and distant markets. In future work we are considering methods to examine a distance function approach distinguishing between multiple outputs, such as local and distant sales. Färe and Primont [26] demonstrated that the output distance function is a natural generalization of the production function for multiple outputs. The issue of whether to specify an output distance function or an input distance function will need to be carefully motivated. The output distance function is the appropriate approach for assessing input contributions and substitution patterns of inputs while the input distance function captures output effects and tradeoffs of outputs. These are more advanced issues that can be addressed after an initial assessment of the impact of local sales on the sustainability of the producer's operation.

\section{Acknowledgements}

The judgments and conclusions herein are those of the authors and do not necessarily reflect those of the U.S. Department of Agriculture. The authors are responsible for all errors.

\section{References}

1. American Farmland Trust. Shortening the distance from farm gate to dinner plate; Available online: http://www.farmland.org/programs/localfood/farmtofork.asp (accessed on 24 December 2009).

2. Ilbery, B.; Maye, D. Food supply chains and sustainability. Land Use Policy 2005, 22, 331-344.

3. Darby, K.; Batte, M.T.; Ernst, S.; Roe, B. Decomposing local: a conjoint analysis of locally produced foods. Am. J. Ag. Econ. 2008, 90, 476-486. 
4. Born, B.; Purcell, M. Avoiding the local trap. J. Plan. Educ. Res. 2006, 26, 195-207.

5. Stephenson, G.; Lev, L. Direct marketing introduction for organic farms. eXtension, 9 December 2009; Available online: http://www.extension.org/article/18376 (accessed on 24 December 2009).

6. Walz, E. Final Results of the Fourth National Organic Farmers' Survey; Organic Farming Research Foundation: Santa Cruz, CA, USA; Available online: http://ofrf.org/publications/ survey.html (accessed on 24 December 2009)

7. Offermann, F.; Nieberg, H. Economic Performance of Organic Farms in Europe. Organic Farming in Europe: Economics and Policy; University of Hohenheim: Stuttgart, Germany, 2001; Vol. 5.

8. Kumbhakar, S.C.; Lovell, C.A.K. Stochastic Frontier Analysis; Cambridge University Press: New York, NY, USA, 2000.

9. Greene, W.H. LIMDEP Version 9.0; Econometric Software: Plainview, NY, USA, 2007.

10. Kurkalova, L.A.; Carriquiry, A. Input- and output-oriented technical efficiency of Ukrainian collective farms, 1989-1992: Bayesian analysis of a stochastic production frontier model. J. Prod. Anal. 2003, 20, 191-211.

11. Lohr, L.; Park, T.A. Choice of insect management portfolios by organic farmers: lessons and comparative analysis. Ecol. Econ. 2002, 43, 87-99.

12. Fraser, I.M.; Horrace, W.C. Technical efficiency of Australian wool production: point5 and confidence interval estimates. J. Prod. Anal. 2003, 20, 169-190.

13. Mathijs, E.; Swinnen, J.F.M. Production organization and efficiency during transition: an empirical analysis of East German agriculture. Rev. Econ. Stat. 2001, 83, 100-107.

14. Whole Foods Market. Locally grown - the whole foods market promise; Available online: http://www.wholefoodsmarket.com/products/locallygrown/index.html (accessed on 24 December 2009).

15. Zellner, A.; Kmenta, J.; Dreze, J. Specification and estimation of Cobb-Douglas production function models. Econometrica 1966, 34, 784-795.

16. Serra, T.; Goodwin, B.K. The efficiency of Spanish arable crop organic farms: a local maximum likelihood approach. J. Prod. Anal. 2009, 31, 113-124.

17. Lohr, L.; Park, T.A. Technical efficiency of U.S. organic farmers: the complementary roles of soil management techniques and farm experience. Ag. Res. Econ. Rev. 2006, 35, 327-338.

18. Kennedy, P.E. Estimation with correctly interpreted dummy variables in semilogarithmic equations. Amer. Econ. Rev. 1981, 71, 801.

19. Krueger, A.B.; Summers, L.H. Efficiency wages and the inter-industry wage structure. Econometrica 1988, 56, 259-293.

20. Reinhard, S.; Lovell, C.A.K.; Thijssen, G. Econometric estimation of technical and environmental efficiency: an application to Dutch dairy farms. Am. J. Ag. Econ. 1999, 81, 44-60.

21. Kumbhakar, S.C.; Tsionas, E.G.; Sipiläinen, T. Joint estimation of technology choice and technical efficiency: an application to organic and conventional dairy farming. J. Prod. Anal. 2009, 31, 151-161.

22. Kotcon, J.; Thilmany, D. CSREES Organic Opportunities White Paper; USDA Cooperative State Research, Education and Extension Service: Washington, DC, USA, 2006. 
23. Coley, D.; Howard, M.; Winter, M. Local food, food miles and carbon emissions: a comparison of farm shop and mass distribution approaches. Food Policy 2009, 34, 150-155.

24. Gilg, A.W.; Battershill, M. To what extent can direct selling of farm produce offer a more environmentally friendly type of farming? Some evidence from France. J. Env. Manag. 2000, 60, 195-214.

25. Morrison Paul, C.J.; Johnston, W.E.; Frengley, G.A.G. Efficiency in New Zealand sheep and beef farming: the impacts of regulatory reform. Rev. Econ. Stat. 2000, 82, 325-337.

26. Färe, R.; Primont D. Multi-Output Production and Duality: Theory and Applications; Kluwer Academic Press: Boston, MA, USA, 1995.

(C) 2010 by the authors; licensee Molecular Diversity Preservation International, Basel, Switzerland. This article is an open-access article distributed under the terms and conditions of the Creative Commons Attribution license (http://creativecommons.org/licenses/by/3.0/). 